\title{
NECESSITY OF ANTIBACTERIAL PROPHYLAXIS IN THE TREATMENT OF RENO-URETERAL LITHIASIS BY EXTRACORPOREAL SHOCK WAVE LITHOTRIPSY. A PROSPECTIVE DESCRIPTIVE STUDY
}

\author{
Andrei BRADU ${ }^{1 凶}$, Emil CEBAN ${ }^{1}$ \\ ${ }^{1}$ Department of Urology and Surgical Nephrology, „Nicolae Testemitanu“ State University of Medicine and \\ Pharmacy, Chisinau, Republic of Moldova \\ Received 03 Apr 2020, Accepted 29 Apr 2020 \\ https://doi.org/10.31688/ABMU.2020.55.2.08
}

\begin{abstract}
Introduction. Due to the increase in the incidence of reno-ureteral lithiasis worldwide from $1 \%$ to $15 \%$, varying according to age, sex, race, and geographical location, extracorporeal shock wave lithotripsy remains the method of choice in the treatment of reno-ureteral lithiasis. The need for antibacterial prophylaxis is required only in well-defined cases, uroculture with antibacterial sensitivity being crucial in order to reduce the infectious complications.

The objective of the study was to evaluate the need for antibiotic administration and to detect risk factors for the development of post-ESWL bacteriuria.

Material and methods. Between 05 Nov 2018 - 10 Dec 2019, a group of 120 patients with the diagnosis of reno-ureteral lithiasis was selected, who underwent ESWL treatment in Department of Urology and Surgical Nephrology from Republican Clinical Hospital „Timofei Mosneaga“. In all 120 patients, urine sample was taken before and after ESWL. In all patients included in the study, uroculture with antibiogram was performed.
\end{abstract}

\section{Résumé}

La nécessité d'une prophylaxie antibactérienne dans le traitement de la lithiase réno-urétérale par lithotripsie extracorporelle par ondes de choc. Une étude descriptive prospective

Introduction. En raison de l'augmentation de l'incidence de la lithiase réno-urétérale dans le monde de $1 \%$ à $15 \%$, variant selon l'âge, le sexe, la race et la situation géographique, la lithotripsie extracorporelle par ondes de choc reste la méthode de choix dans le traitement de la lithiase réno-urétérale . La nécessité d'une prophylaxie antibactérienne est exigée seulement dans des cas bien définis et l'uroculture avec une sensibilité antibactérienne est décisive afin de réduire les complications infectieuses.

L'objectif de l'étude a été l'évaluation de la nécessité d'une administration d'antibiotiques et de détecter les facteurs de risque pour le développement d'une bactériurie post-ESWL.

Matériel et méthodes. Du 5 novembre 2018 au 10 décembre 2019, un groupe de 120 patients avec une lithiase réno-urétérale, qui ont subi un traitement 
Results. The uroculture results obtained before ESWL were positive in 25 (20.84\%) patients without any clinical symptoms and absence of leukocytes in the general urine analysis more than 10 per high power field. At the same time, the number of positive urine culture after ESWL increased significantly in $47 \mathrm{pa}$ tients.

Conclusions. Antibiotic prophylaxis is not justified in the absence of definite risk factors such as positive urine culture before ESWL, JJ stent or nephrostome and a history of infectious reno-ureteral lithiasis or recurrent urinary tract infections.

Keywords: ESWL, reno-ureteral lithiasis, antibacterial therapy. par ESWL au Département d'urologie et de néphrologie chirurgicale de l'Hôpital Clinique Républicain «Timofei Mosneaga» a été sélectionné. Un échantillon d'urine a été prélevé avant et après ESWL chez tous les patients, soit 120 cas. Egalement, une uroculture avec un antibiogramme a été réalisée pour tous les patients inclus à l'étude.

Résultats. Les résultats d'uroculture obtenus avant ESWL ont montré des résultats positifs chez 25 $(20,84 \%)$ patients sans aucun symptôme clinique et l'absence de leucocytes dans l'analyse d'urine générale en nombre de plus de 10 leucocytes par champ visuel du microscope avec puissance élevée. Dans le même temps, le nombre de cultures positives d'urine après ESWL a augmenté significativement chez $47(39,17)$ patients.

Conclusions. La prophylaxie antibiotique n'est pas justifiée dans l'absence du facteur de risque défini par une culture positive d'urine avant ESWL, un stent JJ ou une néphrostomie et des antécédents de lithiase réno-urétérale infectieuse ou infections récurrentes des voies urinaires.

Mots-clés: ESWL, lithiase réno-urétérale, thérapie antibactérienne.

treatment. Endotoxins are another presumed factor involved in the pathogenesis of urinary tract infection and lithiasis ${ }^{8}$. High levels of endotoxins are detected both in infected calculi (struvite and carbonate apatite) and in non-infected calculi. It is considered that high concentrations of endotoxins (lipopolysaccharides) are released into the systemic circulation during lithotripsy treatment, resulting in a systemic inflammatory response syndrome (SIRS), which can lead to sepsis ${ }^{8,9}$. A positive culture for Proteus, Pseudomonas, Klebsiella, Staphylococcus aureus and Staphylococcus epidermidis could be considered a determining factor in the etiology of struvite calculus formation. This will also justify the antibacterial treatment before initiating any therapeutic procedure for calculus fragmentation ${ }^{10,11}$. It is also proven that in patients with negative urocultures before ESWL the risk of developing post-operative infectious complications without the administration of antibiotics is $14 \%{ }^{12}$.

The administration of prophylactic antibacterial drugs remains a controversial issue in patients with sterile urine undergoing ESWL treatment ${ }^{13-15}$. The European Urology Association (EUA) and the recommendations of the American Association of Urology (AAU) have proposed different protocols for prophylaxis of developing post-ESWL infectious complications ${ }^{16}$. According to the AAU recommendations, 
Table 1. Demographic information on patients.

\begin{tabular}{|c|c|c|}
\hline Age (years) & Frequency & Per cent $(\%)$ \\
\hline $\begin{array}{c}18-35 \\
36-59 \\
60-79 \\
\text { Total } \\
\end{array}$ & $\begin{array}{c}35 \\
53 \\
32 \\
120 \\
\end{array}$ & $\begin{array}{c}29.17 \\
44.16 \\
26.67 \\
100 \\
\end{array}$ \\
\hline \multicolumn{3}{|l|}{ Sex } \\
\hline $\begin{array}{c}\text { Male } \\
\text { Female } \\
\text { Total }\end{array}$ & $\begin{array}{l}73 \\
47 \\
50 \\
\end{array}$ & $\begin{array}{c}60.83 \\
39.17 \\
100 \\
\end{array}$ \\
\hline \multicolumn{3}{|c|}{ Calculus localization } \\
\hline $\begin{array}{c}\text { Kidney } \\
\text { Left side } \\
\text { Right side } \\
\text { Bilaterally } \\
\text { Ureter } \\
\text { Total } \\
\end{array}$ & $\begin{array}{c}67 \\
32 / 67 \\
24 / 67 \\
11 / 67 \\
53 \\
120 \\
\end{array}$ & $\begin{array}{c}55.84 \\
47.76 \\
35.82 \\
16.42 \\
44.16 \\
100 \\
\end{array}$ \\
\hline \multicolumn{3}{|l|}{ Calculus size } \\
\hline $\begin{array}{c}<1 \mathrm{~cm} \\
>1 \mathrm{~cm} \\
\text { Total }\end{array}$ & $\begin{array}{c}74 \\
46 \\
120 \\
\end{array}$ & $\begin{array}{c}61.67 \\
38.33 \\
100 \\
\end{array}$ \\
\hline \multicolumn{3}{|c|}{ History of UTI } \\
\hline $\begin{array}{c}\text { Yes } \\
\text { No } \\
\text { Total } \\
\end{array}$ & $\begin{array}{c}34 \\
86 \\
120 \\
\end{array}$ & $\begin{array}{c}28.3 \\
71.66 \\
100 \\
\end{array}$ \\
\hline \multicolumn{3}{|c|}{$\begin{array}{c}\text { History of surgery caused } \\
\text { by lithiasis }\end{array}$} \\
\hline $\begin{array}{c}\text { Yes } \\
\text { No } \\
\text { Total }\end{array}$ & $\begin{array}{c}27 \\
93 \\
120\end{array}$ & $\begin{array}{l}22.5 \\
77.5 \\
100\end{array}$ \\
\hline
\end{tabular}

prophylactic antibiotic therapy is required in a single dose 24 - 48 hours before ESWL ${ }^{15-17}$. At the same time, in patients with urinary stents or in the presence of possible infected calculi it is necessary to administer antibiotics for 5 days after ESWL ${ }^{17}$.

\section{THE OBJECTIVE OF THE STUDY}

To assess the need for antibiotic administration and to detect risk factors for the development of post-ESWL bacteriuria.

\section{Material AND MEthods}

Between 05 Nov 2018 - 10 Dec 2019, a group of 120 patients with the diagnosis of reno-ureteral lithiasis was selected, who underwent ESWL treatment in Department of Urology and Surgical Nephrology from Republican Clinical Hospital „Timofei Mosneaga“, Chisinau, Republic of Moldova. The patients' urine sample was taken before and after ESWL. In all patients included in the study, uroculture with antibiogram was performed. Statistical analysis was performed with Epi-Info 7 and Excel. Statistical significance was evaluated using Fisher's
Table 2. Results of urine culture test before ESWL.

\begin{tabular}{ccc}
\hline $\begin{array}{c}\text { Urine culture results before } \\
\text { ESWL }\end{array}$ & Frequency & $\begin{array}{c}\text { Percentage } \\
(\%)\end{array}$ \\
\hline Negative urine culture & 95 & 79,16 \\
Positive urine culture & 25 & 20,84 \\
Escherichia coli & 4 & 3,33 \\
Enterococcus faecalis & 2 & 1,66 \\
Klebsiella pneumoniae & 13 & 9,16 \\
Proteus mirabilis & 4 & 3,33 \\
Staphylococcus aureus & 2 & 1,66 \\
Streptococcus agalac. & 2 & 1,66 \\
Total & 120 & 100 \\
\hline
\end{tabular}

Table 3. Results of urine culture test after ESWL.

\begin{tabular}{ccc}
\hline $\begin{array}{c}\text { Urine culture results after } \\
\text { ESWL }\end{array}$ & Frequency & Percentage (\%) \\
\hline Negative urine culture & 73 & 60.83 \\
Positive urine culture & 47 & 39.17 \\
Escherichia coli & 15 & 12.5 \\
Enterococcus faecalis & 4 & 3.33 \\
Klebsiella pneumoniae & 16 & 13.34 \\
Proteus mirabilis & 4 & 3.34 \\
Staphylococcus aureus & 5 & 4.16 \\
Streptococcus agalac. & 3 & 2.5 \\
Total & 120 & 100 \\
\hline
\end{tabular}

exact test, with $\mathrm{p}<0.05$ considered statistically significant. The study was approved by the Research Ethics Committee decision no. 49/40 of May 10, 2016 of „Nicolae Testemitanu“ State University of Medicine and Pharmacy, Chisinau, Republic of Moldova.

\section{Results}

Of the 120 patients included in the study, $73 \mathrm{pa}-$ tients were men (60.83\%) and $47(39.17 \%)$ were women, mean age 43 \pm 15 years, ratio men:women 1.9:1. The following comorbidities were found: 10 (20\%) patients - high blood pressure, $5(10 \%)$ patients diabetes mellitus. Of the 120 patients included in the study, there were $67(55.84 \%)$ patients with renal calculi, of which $11(16.41 \%)$ patients with bilateral kidney calculi; 53 patients from 120 (44.16\%) had calculi located in the upper, middle, and lower ureter. All patients were subjected to ESWL for calculi treatment, of which 15/120 (12.5\%) patients were placed a double JJ stent before ESWL. The calculi size ranged from $0.6 \mathrm{~cm}$ to $2 \mathrm{~cm}( \pm 0.48 \mathrm{~cm})$ (Table 1$)$.

The uroculture results before ESWL were positive in $25(20.84 \%)$ patients without any clinical symptoms and the absence of leukocytes in the general urine analysis more than 10 per high power field (Table 2).

At the same time, the number of positive urine cultures after ESWL increased significantly in $47 \mathrm{pa}$ tients (Table 3). 
The Proteus microorganism was positive in patients both with a history of urinary tract infection and surgery.

\section{Discussion}

There is obviously controversy regarding the need for pre- and post-ESWL antibacterial prophylaxis, which is also highlighted by the differences in the AAU and EAU recommendations ${ }^{14,18-19}$. The AAU good practice statement on antimicrobial prophylaxis for minimally invasive interventions including ESWL states that antibiotic prophylaxis is indicated in all patients, with a single dose of antibiotic administered over 24 hours after ESWL ${ }^{20,21-22}$. This recommendation is based on a meta-analysis by Salem and Sharma evaluating 8 randomized clinical trials and 6 clinical studies ${ }^{16,17}$. The meta-analysis of these authors demonstrated a reduction in the median probability of developing post-ESWL - UTIs, from 5.7\% without antibacterial treatment up to $2.1 \%$ in patients with antibiotic treatment ${ }^{16,17}$. Alternatively, the EAU guidelines for urological infections recommend only prophylaxis in cases of „stent, due to increased bacterial load (e.g., JJ stent, nephrostome, or infectious calculi)" ${ }^{\text {"18 }}$.

An unique prospective cohort study of $120 \mathrm{pa}-$ tients with pre- and post-ESWL urocultures, without antibiotic prophylaxis, analyzed the risk factors which could be linked to a positive urine culture ${ }^{21}$. Factors considered were sex, age, diabetes, hypertension and history of previous surgery (including JJ stent, or nephrostome), personal history of UTIs, calculi size, chemical structure, or location ${ }^{2,7,7,12}$. It was found that in patients with a history of UTIs and surgery or the presence of JJ stent administration of antibiotic after ESWL is statistically significant justified, according to the statistical analysis of the study $(p=0.04)$. These studies support the EAU recommendations that routine prophylaxis for ESWL patients with sterile urinary cultures is not required ${ }^{18-20}$. However, patients with a history of UTI and previous surgical intervention (ureteral stent or nephrostome) are recommended to follow antibacterial prophylaxis before ESWL ${ }^{18-20}$. In this prospective study, it was shown that sex, age, calculus size are risk factors for the development of UTI. Moreover, this study has demonstrated that the presence of JJ stent or nephrostome before ESWL is a risk factor for bacteriuria after ESWL ${ }^{18,19,21}$. At the same time, the need for universal antibiotic prophylaxis prior to ESWL is not recommended because the development of UTI is low in patients with negative urinary cultures ${ }^{16,21,22}$. This shows that antibiotics are not required in these patients, having no benefit in reducing infectious complications and presenting an increased risk of bacterial resistance and side effects ${ }^{20-22}$.

\section{Conclusions}

Antibacterial prophylaxis is not justified in the absence of definite risk factors, such as positive urine culture before ESWL, JJ stent or nephrostome and a history of infectious calculi or recurrent UTIs. The unjustified administration of antibacterials has no benefits and may present some risks of increased bacterial resistance and side effects.

\section{Author Contributions:}

Conceptualization, A.B. and E.C.; methodology, A.B.; software, A.B; validation, E.C. and A.B.; formal analysis, E.C.; investigation, A.B.; resources, A.B; data curation, E.C. and A.B.; writing-original draft preparation, A.B.; writing-review and editing, A.B, E.C.; visualization, E.C. and A.B.; supervision, E.C.; project administration, E.C. All the authors have read and agreed with the final version of the article.

\section{Compliance with Ethics Requirements:}

„The authors declare no conflict of interest regarding this article"

„The authors declare that all the procedures and experiments of this study respect the ethical standards in the Helsinki Declaration of 1975, as revised in 2008(5), as well as the national law. Informed consent was obtained from all the patients included in the study"

"No funding for this study"

\section{Acknowledgements:}

None

\section{References}

Alexander CE, Gowland S, Cadwallader J, Hopkins D, Reynard JM, Turney BW. Routine antibiotic prophylaxis is not required for patients undergoing shockwave lithotripsy: outcomes from a national shockwave lithotripsy database in New Zealand. Journal of Endourology. 2016;30(11):1233-1238.

Ceban E. The treatment of the reno-ureteral calculi by extracorporeal shockwave lithotripsy (ESWL). Journal of Medicine and Life. 2012;5(2):133.

Chung DY, Lee JY. Recommendations for antibacterial prophylaxis in endourological procedures. Urogenital Tract Infection. 2019;14(1):1-8.

Deki S, Amit A. A descriptive study of morbidity profile after ESWL for urolithiasis. International Journal of Scientific Research. 2020;9(1).

Duvdevani M, Lorber G, Gofrit O, et al. Fever after shockwave lithotripsy-risk factors and indications for prophylactic antimicrobial treatment. Journal of Endourology. 2010; 24(2): 277-281. 
Socea B, Nica AA, Bratu O, et al. Incidental finding of a sigmoid intussusception associated with rectal prolapse - a case report. Arch Balk Med Union. 2018;53(1):143-146.

Ebrahim MAM, Alnaib Z, Aljuboori Z, Osman E. Amikacin as the most potent antibiotic locally, is it required prior to extracorporeal shock wave lithotripsy (ESWL) in patients with double J stents. Med Sur Urol. 2019;8:215.

Ghazimoghaddam B, Tajari H, Gholipoor M, Balmehd M. Antibiotic prophylaxis during extracorporeal shock wave lithotripsy in the prevention of urinary tract infections in patients with sterile urine before the procedure. Journal of Clinical and Diagnostic Research. 2011;5(4):772-774.

Lantz AG, McKay J, Ordon M, et al. Shockwave lithotripsy practice pattern variations among and between American and Canadian urologists: in support of guidelines. Journal of Endourology. 2016;30(8):918-922.

Lu Y, Tianyong F, Ping H, Liangren L, Haichao Y, Qiang W. Antibiotic prophylaxis for shock wave lithotripsy in patients with sterile urine before treatment may be unnecessary: a systematic review and meta-analysis. The Journal of Urology. 2012;188(2):441-448

Mahamat MA, Diarra A, Kassogué A, et al. Renal colic: epidemiological, clinical etiological and therapeutic aspects at the urology department of the National Reference General Hospital of N'Djamena (Chad). Open Journal of Urology. 2020;10(02):25.

Moreno AM, Lirola MDM, Tabar PJG, Baena JFG, Tenza JAT, Encinas JJ. Incidence of infectious complications after extracorporeal shock wave lithotripsy in patients without associated risk factors. The Journal of Urology. 2014;192(5):1446-1449.
Mourmouris P, Tzelves L, Skolarikos A. Complications after active stone removal. Current Opinion in Urology. 2020;30(2):135-143.

Mrkobrada M, Ying I, Mokrycke S, et. al. CUA Guidelines on antibiotic prophylaxis for urologic procedures. Canadian Urological Association Journal. 2015;9(1-2):13.

Pradère B, Doizi S, Proietti S, Brachlow J, Traxer O. Evaluation of guidelines for surgical management of urolithiasis. The Journal of Urology. 2018;199(5):1267-1271.

Salem S, Mehrsai A, Zartab H, Shahdadi N, Pourmand G. Complications and outcomes following extracorporeal shock wave lithotripsy: a prospective study of 3,241 patients. Urological Research. 2010;38(2):135-142.

Sharma NL, Alexander CE, Grout E, Turney BW. Shock-wave lithotripsy: Variance within UK practice. Urolithiasis. 2017;45(2):193-201.

Türk C, Petř́ik A, Sarica K, et al. EAU guidelines on interventional treatment for urolithiasis. European Urology. 2016;69(3):475-482.

Wagenius M, Jakobsson J, Stranne J, Linder A. Complications in extracorporeal shockwave lithotripsy: a cohort study. Scandinavian Journal of Urology. 2017;51(5):407-413.

Wang RC. Managing urolithiasis. Ann Emerg Med. 2016;67(4):449-454.

Wollin DA, Joyce AD, Gupta M, et al. Antibiotic use and the prevention and management of infectious complications in stone disease. World Journal of Urology. 2017;35(9):1369-1379.

Zumstein V, Betschart P, Abt D, Schmid HP, Panje CM, Putora PM. Surgical management of urolithiasis-a systematic analysis of available guidelines. BMC Urology. 2018;18(1):25. 